\title{
Robotic Solutions for Sewage Systems in Coastal Urban Environments
}

\author{
Antoni Grau, Yolanda Bolea \\ Automatic Control Dept. \\ Technical University of Catalonia, UPC \\ Barcelona, Spain \\ antoni.grau@upc.edu
}

\author{
Ana Puig-Pey, Alberto Sanfeliu \\ Institute of Robotics \\ Technical University of Catalonia, UPC/CSIC \\ Barcelona, Spain
}

\begin{abstract}
The objective of this article is to present a specific urban challenge proposed by European cities in ECHORD++ project that can be the starter point of new innovative public procurements. The project that was selected by the project leading team has been a robotic solution for monitoring the sewage system of a European city. Cities are prepared and the Research and Technological Development (RTD) consortia are waiting for real opportunities. The take-off of the robotic technology could be possible: from Lab to Market addressing real urban needs of citizens and cities. The proposals obtained in ECHORD++ could be followed by other cities.
\end{abstract}

Keywords-Urban Robotics, Sewage Systems, Pre-commercial Procurement.

\section{INTRODUCTION}

Europe has a long tradition of outstanding research and manufacturing in robotics. However, finding common ground between manufacturers and the research community has proven difficult in the past. Defining the future direction of robotics research has revealed to be the real challenge. ECHORD++, [1], was installed as an incubator to promote innovation by facilitating the cooperation between academia and industry. ECHORD++ wants to further stimulate this interaction between robot manufacturers, researchers and users. This goal will be achieved by implementing three different instruments: i) the experiments, ii) Pre-Commercial Procurement (PCP) and iii) Robotic and Innovation Facilities (RIFs).

These tools are tailor-made to meet the needs of the innovative robotics technologies of the manufacturing industry (mainly SMEs with small lot sizes and the need for highly flexible solutions) and public bodies, looking for robotics technology with basic functions at competitive prices for tender processes). In all cases, the research will be done by academic partners or research institutes in conjunction with the potential user of the robotics technology. ECHORD++ is a research Project funded by EU 7th Framework Program that has as main objective to give solutions to the demands proposed by public bodies in European cities.

The ECHORD++ pursues also to fulfill with European directives about Sustainability, [2]. The context of this proposal is fourfold. First, despite progress in some areas, major environmental challenges remain, as well as opportunities to make the environment more resilient to systemic risks and change. Second, the EU has adopted the Europe 2020 Strategy for Smart, Sustainable and Inclusive Growth, which guides policy development for the period up to 2020. Third, while many Member States are struggling to cope with the economic crisis, the need for structural reforms offers new opportunities for the EU to move towards an inclusive green economy. Finally, Rio +20 highlighted the importance of the global dimension. Under these premises, all the public bodies proposals have been evaluated taking into account this dimension.

Regarding the PCP side (called also PDTI, Public end-user Driven Technological Innovation), ECHORD++ consists of different stages: initially, local authorities in city councils analyse the existing problems in the city that should be solved in a technological manner (by means of a robotized solution); each city can present a unique proposal in a public call; secondly, when all the presented proposals are collected a panel of experts score and rank them following some specific indicators (citizen's needs, social impact, sustainability impact, economic impact, efficiency...), only the best ranked proposal wins and this proposal will be "the challenge" to be solved; then, the proposal is refined by the winner city and presented, a public call is open to consortia (research centres and private companies) as a European project and only the two best ranked solutions are accepted to be working to solve the challenge. These two consortia are funded by ECHORD++ project to work in parallel for solving the challenge. At the end of this process of 36 months, the best prototype is considered for industrial production and deployment. Some relevant outcomes are expected from both teams in terms of productivity and edge technology, as well as patents and impact actions to promote the research results.

\section{Methodology}

\section{A. The Process}

The process consisted of a selection among 24 European cities and finally the city of Barcelona won the challenge in Urban Robotics with a call for the project "Robots for the inspection and the clearance of the sewer network in cities". After this selection an open call was performed by 
ECHORD ++ administration and a total of 10 consortiums applied for the project. Finally two consortiums were selected to develop their research in this challenge, ending up with a real prototype which will be presented at the end of the 36month project. Some specific European regulations exist regarding this subject (Regulation (EC) No 1013/2006, and Decision No 1386/2013/EU) [3]. To develop this research project, proposers have to follow the Barcelona city regulations in this matter, Environmental Municipal Ordinance (1999) [4]. As a coastal city, the inspection of sewage has a clear implication in the pollution of the sea, and regulations are stricter than in other non-coastal cities. The challenge is twofold therefore, and the requirements on the robotics solutions have to be followed with special care.

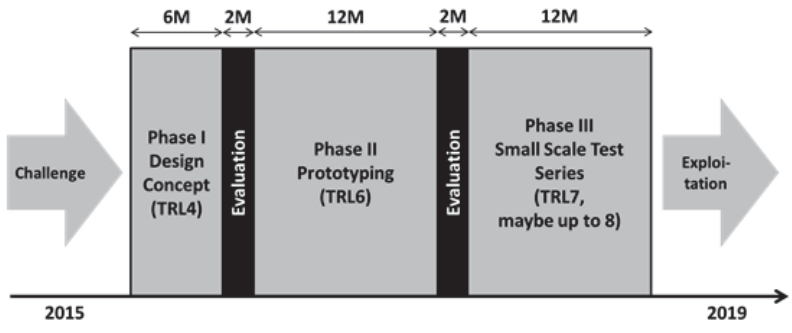

Fig. 1.Process diagram from the Challenge to the prototype explotation.

The technology development of the PDTI will take place in three phases:

1. System design (duration 6 months, 3 R\&D consortia per scenario)

2. Prototyping (duration 12 months, 2 R\&D consortia per scenario)

3. Small-scale test series (duration 12 months, 2 R\&D consortia per scenario).

For the first phase, three consortia per scenario are selected, and two out of them will be selected for the remaining phases based on the outcome of the system design after the first 6 months of sys-tem design work. The timeline is illustrated in Fig. 1. The Phase I of the PDTI establishes the design of the technological solution and has to show how the robotic solution will perform the different tasks assigned in the Challenge Brief specifications. The evaluation of the three technological proposals at the end of the Phase I will be based on marks given according to three basic criteria:

- Scientific and/or technological excellence

- Quality and efficiency of the implementation and the operative management.

- Potential Impact through the development, dissemination and use of project.

\section{B. The Challenge}

Sewer inspections require many people to work in risky and unhealthy conditions. Introducing a robotic solution in this process aims at reducing the labour risks, improving the precision of sewer inspections and optimizing sewer cleaning resources of the city. This system should be able to determine the state of the sewer in order to identify sewer segments where its functionality has been reduced either by sediments or by structural defects. The coastal pollution is another issue to be treated for those robotic solutions. Human sewage largely consists of excrement from toilet-flushing; wastewater from bathing, laundry, and dishwashing; and animal and vegetable matter from food preparation that is disposed through an insink garbage disposal. Because coasts are densely populated, the amount of sewage reaching seas and oceans is of particular concern because some substances it contains can harm ecosystems and pose a significant public health threat. In addition to the nutrients which can cause overenrichment of receiving waterbodies, sewage carries an array of potentially disease-causing microbes known as pathogens. Other functionalities required are sewer monitoring and water, air and sediment sampling. To well carry out these tasks, some general functions are required like remote operation, video and images capture, scanning and map building, among others.

\section{THE SEWAGE}

The current need of the City of Barcelona is to mechanize sewer inspections in order to reduce the labour risks, objectify sewer inspections and optimize sewer cleaning expenses of the city. The sewer network of Barcelona is $1532 \mathrm{~km}$ long, from which approximately $50 \%$ is accessible, which means that the pipe is at least $1.5 \mathrm{~m}$ high and workers are allowed to go inside it. In order to determine the state of the network, visual inspections are done with different frequencies depending on the slope and other characteristics of the sewer. Workers walk all along the pipe, in some sections even four times a year, and decide where it is necessary to clean. Moreover, sewers are classified as confined spaces which require special health and safety measures, in addition to other risks like slippery sections, obstacles or biological risks from the eventual contact with wastewater.

These features made the process of sewer inspection a risky and expensive process that requires improvements urgently. Sewer inspection is a service included in the public management of the sewers of Barcelona. Nowadays, sewer inspections are done by people performing visual inspections and collecting information about the state of the sewage like sediment level and type, pipe obstructions, etc. Because of the sewer risks, the performance of the inspections is about $1.5 \mathrm{~km}$ of sewer every 6 hours. This methodology requires approximately 1 million Euros per year in staffing expenses only, excluding equipment, machinery, health and safety measures, or other expenses.

The task is not easy and the budget is completely justified. When thinking in the robotic operation, the task is even harder than in the human operation. The problems that any robot can find in the sewer pipe are of huge complexity. Some details of the problems that can be encountered in the sewer pipes is shown in Fig. 2, for instance, sewer obstruction, in Fig. 3, connection in pipes with different sections, or in Fig. 4, transversal pipes reducing the section. These are just a few examples showing the big challenge that a robotic system has to face in such a hazardous environment. 


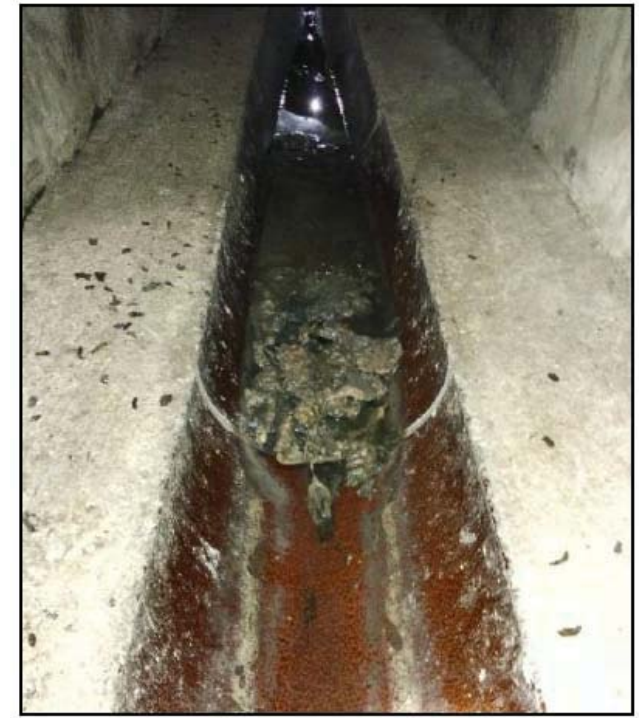

Fig. 2. Sewer obstruction.

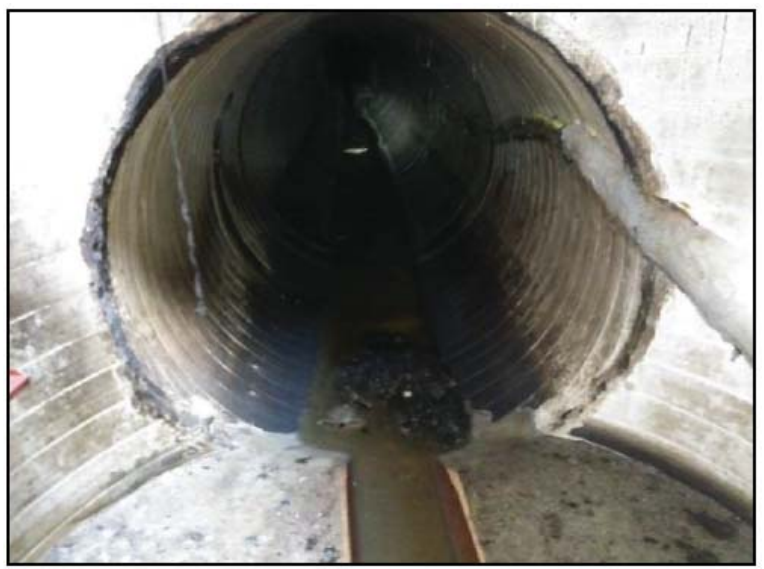

Fig. 3. Connections between pipes.

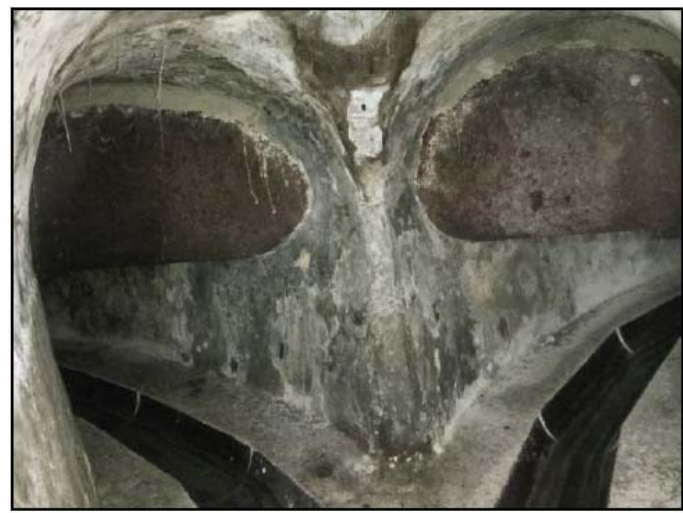

Fig. 4. Section reduction by transversal pipes.
There are different kinds of sewage, with different sections, and some of them allow the pass of people to monitor the network. In other areas the section is too small and only robotic systems are allow to go through, the technical challenge is very huge, see Fig 5.

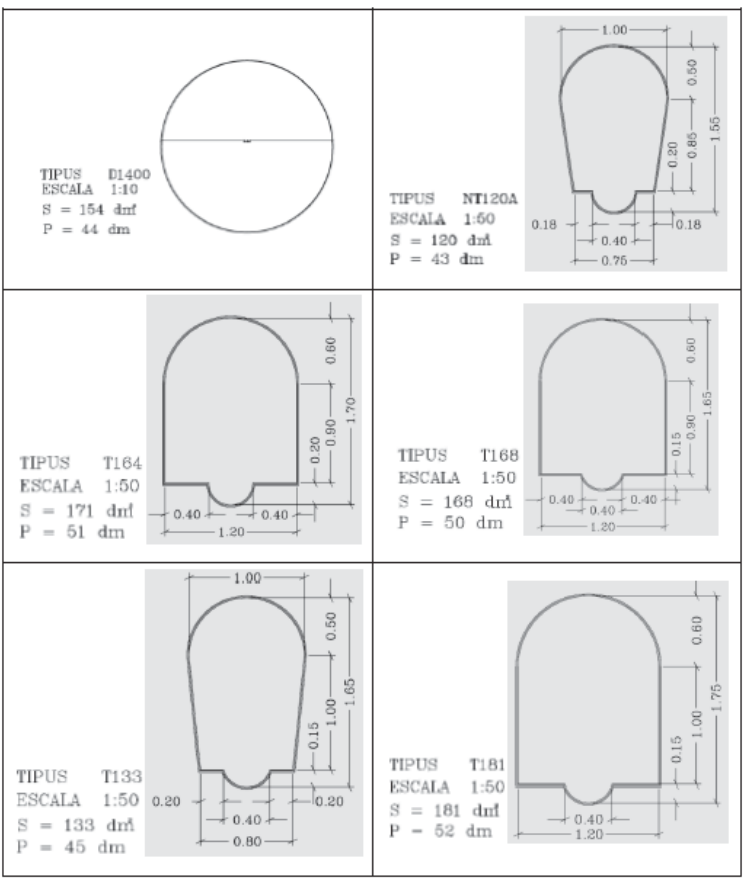

Fig. 5. Different sewer pipe sections.

All the network in equipped with a sophisticated sensory systems that allows the control of this sewage opening or closing different path for water depending on the weather conditions or alarms. This control is supervised in center located at BCASA headquarters, the company that is in charge of the Barcelona's sewage network, see Fig. 6.

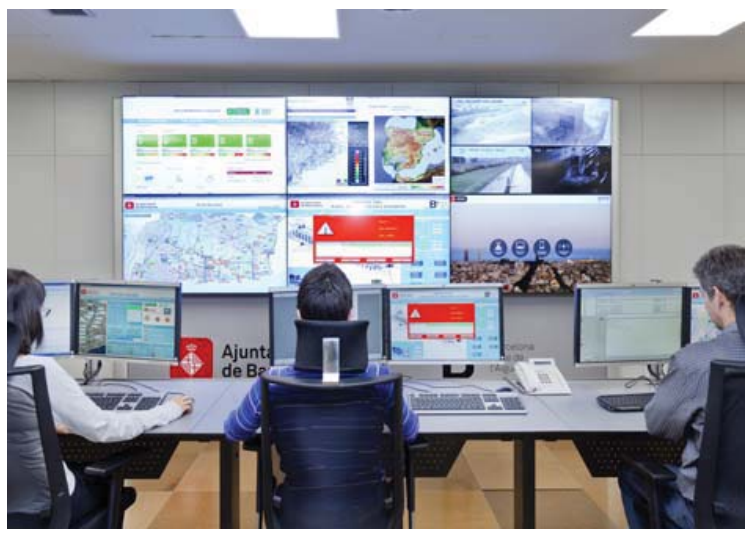

Fig. 6. Control center for Barcelona sewage network. Courtesy of BCASA company [5]. 
There is no regulation that applies to this public service except for the prevention of occupational hazards and, in particular, the regulation of access to confined spaces. The city is willing to amend the legislation of its jurisdiction for introducing this new technology. Barcelona sewage system network has a wide variety of sewers. This enables us to test the technology in various sewer sizes and facilitates the transfer of the technology to other cities.

\section{RESUltS}

The requirements for the new technology are given by the inherent sewer characteristics, that is, different ranges of pipe sizes, possible high concentration of, not explosive, but toxic gases as hydrogen sulphide, slippery areas, obstacles, atmosphere with $100 \%$ humidity, water temperature $16{ }^{\circ} \mathrm{C}$, and no telecommunication coverage in the sewer. The devices that could be considered as robots are able to move themselves in one direction by sewer and record video in $360^{\circ}$ to register the state of the sewer, they have to analyse the sewer by zooming and navigating in $360^{\circ}$ by the video images, they need to access into the sewer system at one point and being recuperated in other point in an autonomous way, they are equipped with cameras, LASER, Lidar and Inertial navigation systems, Sonar sensor (for underwater detection if there is some stream of water) and hydrogen sulphide sensor. With all data collected by the sensors, it is possible to generate a model of the interior of the sewer and identify the possible impairments. The improvements in the existing technology that this project seeks are to facilitate real-time decision making, innovation that makes inspection devices more autonomous, to have more degrees of freedom to move around the network, and the possibility to intensify the checking of a zone where impairment has been detected.

The objective of developing this new technology is to mechanize sewer inspections in order to reduce the labour risks, objectify sewer inspections and optimize sewer cleaning expenses of the city. Specifically, as a result of the challenge definition, there are two tasks that require particular robotics solutions: i) sewer monitoring, and ii) sewer sampling.

\section{A. Sewer monitoring}

The objective of sewer monitoring is to approximate the robot to the maximum level of sensitivity which will allow the sewer manager to make decisions without exposing to risky locations. Fig. 7 illustrates a manual monitoring operative which will be changed for a robotized operational process. Among other reasons, robotized sewer monitoring is extremely useful:

- To avoid access to sewers at risk situations

- To decide safety and health measures for staff

- To locate and follow spills or leaks, normally illegal, in order to protect sewer infrastructures from abrasion, rust and aggressive spills

- To determine tendencies in compounds (seasonal, daily, etc.)

- As a tool for environmental research in sewers
It would be highly recommendable to incorporate to the robot the following functions:

1) Air Sensors

Knowing the environmental quality of the sewers is very important to determine both safety parameters and odours occurrence. Improvements in the former could help to reduce risk situations and optimize human resources. Besides, the last is a very important issue for managers due to the increasing citizen's sensitiveness.

- - Temperature $(\mathrm{T})$

- - Relative Humidity (\%RH)

- - Carbon Monoxide (CO)

- - Hydrogen sulphide (SH2)

- - Methane (CH4)

- - Oxygen $(\mathrm{O} 2)$

- - Lower explosive limit (LEL)

- - Volatile organic carbons (VOCs)

2) Water sensors

The knowledge of the water quality with real time monitoring is interesting for detecting tendencies in compounds (seasonal, daily, etc.) that flow along sewers. Complementing this functionality, punctual changes detected in water quality can alert about spills.

- $\quad$ Temperature (T)

- $\mathrm{pH}$

- $\quad$ Conductivity

- $\quad$ Turbidity

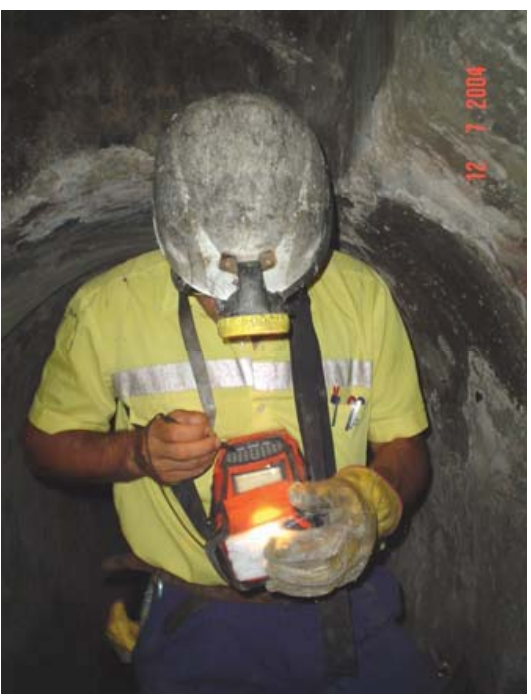

Fig. 7. Example of sewer monitoring 


\section{B. Sampling system}

Sampling objectives are the very same of monitoring systems. Furthermore, sampling systems in sewer networks, as a second step or as a complement after monitoring, is greatly important in order to obtain valid and traceable information which could be used afterwards to determine environmental legislation and policies. Fig. 8 shows just a sample of the huge amount of illegal spills in the sewage system. Automatic sampling is very important to control and prosecute such spills.
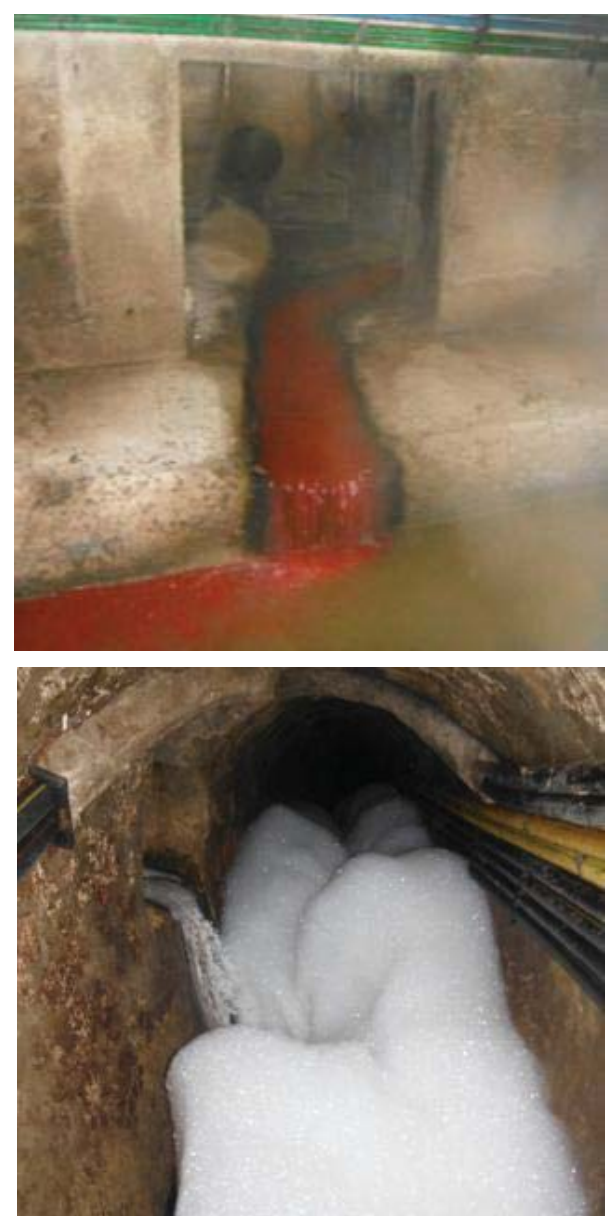

Fig. 8. Examples of spills: up) dye spill, down) detergent spill.

It is difficult to establish a minimum volume required per sample, as this depends on the parameters to be analyzed. However, at least the minimum following volumes would be necessary:
- Water sampling: $300 \mathrm{ml}$ (higher volumes will have greater value)

- Air sampling:

- Passive sampling system like active carbon filters (for instance, $530 \mathrm{mg}$ of active carbon)

- Active sampling system like air capsules

- Sediments sampling: $300 \mathrm{ml}$

\section{CONCLUSIONS}

Access to confined spaces has always been a problem to deal with. Because of that, Barcelona city has developed a very specialized staff in entering into this kind of infrastructures, but the need of improving this method, making it more affordable and available, has been detected in other municipalities of the Barcelona Metropolitan Area and abroad in Spain. In these cases, where the public administration could not afford this service, walking sewers were simply not inspected. Thus, the new technology is expected to really improve the current inspection methodology by reducing the health risks for workers and making it affordable to public administrations, and also by reducing the pollution in sewage that can affect urban coastal areas. This urban challenge is expected to: i) improve sewer workers health and safety measures; ii) improve the public service given since it optimizes the sewer cleaning resources; iii) improve the quality of life of citizens since it will improve the sewer performance.

\section{ACKNOWLEDGMENT}

Authors would like to thank the European Commission for launching ECHORD++ project. The "ECHORD++ EU Project FP7-ICT-2012-601116" project has received funding from the European Union's Seventh Framework Programme for research, technological development and demonstration.

\section{REFERENCES}

[1] ECHORD++ project website: http://echord.eu, last access: April $14^{\text {th }}$, 2017.

[2] Decision No $1386 / 2013 /$ EU of the European Parliament and of the Council of 20 November 2013 on a General Union Environment Action Programme to 2020 'Living well, within the limits of our planet' Text with EEA relevance: 32013D1386.

[3] Regulation (EC) No 1013/2006 of the European Parliament and of the Council of 14 June 2006 on shipments of waste: 32006R1013.

[4] Environmental Municipal Ordinance, http://www.mediambient.bcn.es/cat/web/cont_leg_legs.htm, no. 143 , 16.06.1999, last accessed: April $14^{\text {th }} 2017$.

[5] BCASA website, http://www.clabsa.es/, last accesses April 14 2017. 